Historia y comunicación social

ISSN: $1137-0734$

http://dx.doi.org/10.5209/hics.68720

\title{
Las representaciones de China posrevolucionaria en los escritos de los viajeros argentinos $(1949-1966)$
}

\author{
Tingting $\mathrm{Xia}^{1}$; Salvador Marinaro ${ }^{2}$
}

Recibido el: 8 de abril de 2020 / Aceptado: 31 de octubre de 2020

Resumen. Las formas en las que China fue imaginada por los países occidentales suelen oscilar entre polos opuestos: pueblo civilizado, dueño de una cultura milenaria, o país atrasado y bárbaro; horizonte revolucionario o gobierno despótico y autoritario. En este sentido, los estudios que vinculan a China con América Latina han prestado poca atención a la formación de una imagen moderna en los países de habla hispana durante las primeras décadas luego de la fundación de la República Popular, así como tampoco se ha estudiado en profundidad cuáles fueron los actores específicos en este proceso. A partir de la década de 1950, el gobierno de Pekín inició una política para recibir a una serie de intelectuales de países del denominado "Tercer Mundo": África, el Sudeste Asiático y América Latina. Muchos de los pensadores invitados, a su regreso, publicaron notas, reseñas y libros de crónicas que narraban sus experiencias. Este trabajo analiza las representaciones de la "Nueva China" en los artículos publicados en revistas entre 1949 y 1966 por intelectuales argentinos que visitaron el país asiático. A través de sus narraciones, se construye un discurso que se opone al orientalismo europeo y plantea una primera recepción latinoamericana de la Revolución China.

Palabras clave: Representación de China; los sesentas; Argentina; Diplomacia Cultural; Tercer Mundo.

\section{[en] Image of the Post-revolutionary China in the Writings of the Argentinean Travelers between 1949-1966}

\begin{abstract}
China's image in the eyes of western countries usually oscillates between extreme poles, such as the civilized people, owners of an ancient culture and an underdeveloped country; a revolutionary horizon and a despotic authoritarian government. In this sense, studies that attempt to associate China with Latin America have paid little attention to the modern configuration of China's image in Spanish-speaking countries during the first decade after the founding of the People's Republic of China, let alone the specific actors in this process. Beginning in the 1950s, the Beijing government initiated a diplomatic policy under which a series of intellectuals from Latin America, Africa and, to a lesser extent, Europe were invited to China. Upon arrival, many of them published articles, reviews and chronicle books to share their experiences. This paper analyzes the representation of the "New China" through articles published in the magazines between 1949 and 1966 by Argentinean intellectuals who had visited China. Through their narratives, a discourse that opposes European orientalism is constructed, which also forms the first Latin American reception of Chinese revolutions.
\end{abstract} Keywords: China Imagology; the sixties; Argentina; Cultural Diplomacy; Third World.

Sumario: 1.Introducción. 2.Las relaciones entre China y Argentina: los intelectuales como agentes diplomáticos. 3.El pueblo chino como sujeto del poder político: contraposición entre la democracia "burguesa" y la popular. 4.El pueblo y la riqueza: transformaciones económicas de la "Nueva China". 5.Entre la tradición y el surgimiento de un arte popular: la visión de los argentinos sobre la cultura en la China posrevolucionaria. 6.Las antípodas se encuentran: la lógica de las representaciones sobre China. 7.Conclusión. Bibliografía

Cómo citar: Xia, T; Marinaro, S. (2021) Las representaciones de China posrevolucionaria en los escritos de los viajeros argentinos (1949-1966), Historia y comunicación social 26(1), 121-130.

\section{Introducción}

Desde la publicación del libro clásico de Edward Said (1978), Orientalismo, los investigadores sociales se han mostrado particularmente interesados en los modos en que Oriente fue representado por las sociedades occidentales. Si bien este tipo de análisis ha tenido un amplio desarrollo en las últimas décadas, tantos en las

Universidad de Shanghái, Shanghái, China

E-mail: xttrain@163.com

2 Universidad de Fudan, Shanghái, China

E-mail: salvadormarinaro@gmail.com

Hist. comun. soc. 26(1) 2021: 121-130 
academias occidentales como en las asiáticas ${ }^{3}$, todavía se desconoce el desarrollo de una imagen moderna ${ }^{4}$ de China en los países de habla hispana y particularmente en América Latina. En esta formación discursiva intervinieron actores culturales e instituciones, como revistas y publicaciones, además de las políticas gubernamentales.

Si bien durante los siglos XVII y XVIII el país asiático era reconocido por su sofisticación, las representaciones europeas cambiaron rotundamente luego de la Revolución Industrial inglesa. Los escritos de viajes del siglo XVIII y XIX, al mismo tiempo que representaban uno de los primeros contactos a nivel cultural, hicieron hincapié tanto en el autoritarismo asiático como en el retraso material y social que justificaba el expansionismo europeo. Sin embargo, el triunfo de la Revolución China generó dos discursos contrapuestos: por un lado, la idea de una utopía socialista; y por otro, la idea de una amenaza externa que se reproducían en los medios de comunicación y discursos intelectuales desde los años cincuenta (Zhou, 2006).

Históricamente la perspectiva latinoamericana estuvo influenciada por el orientalismo europeo, pero la Primera Guerra Mundial significó una pérdida de prestigio de la cultura del viejo continente (Gasquet, 2006). El antiimperialismo, la proliferación de un sentimiento de solidaridad entre pueblos subyugados económica o políticamente, y el surgimiento del Movimiento del Tercer Mundo implicó una nueva imagen de aquellas naciones que luchaban por liberarse de la opresión colonial europea (Bergel, 2015: 15). Esto se sumó a una política activa del gobierno de Mao Zedong que buscó, a través de canales no formales, incentivar los vínculos económicos y culturales con diversos países del bloque occidental (Oviedo, 2010).

A partir de 1949, Pekín inició una política diplomática dirigida a intelectuales provenientes de África, el Sudeste Asiático y América Latina. El objetivo era invitarlos al país para que "conocieran la auténtica China" (Olivier y Frontini, 1954: 10). Al respecto, en los últimos años diversos estudios han indagado en la particularidad de estos viajes, en tanto representaron el primer intercambio entre intelectuales de América Latina y China (Saítta, 2007; Montt Strabucchi, 2016; Hubert, 2017; Rupar, 2020). De acuerdo con estas investigaciones, los escritos de los viajeros tenían un valor literario propio, a pesar de que sus experiencias estaban atravesadas por un fuerte sentido político e ideológico.

En la década de los cuarenta, la visión latinoamericana de una lucha global contra el imperialismo produjo un sentimiento en común con China. Esta interpretación estuvo vinculada con la formación de una inteligentzia comprometida en la política de América Latina. Los debates entre los actores culturales y el Partido Comunista fueron la plataforma para la construcción de una imaginación utópica sobre China, que se incorporó como segundo horizonte revolucionario después de la Unión de Repúblicas Socialistas Soviéticas (URSS).

Dada las características del campo intelectual, su larga tradición y sus repercusiones en el resto de América Latina, este artículo se centra en los intelectuales argentinos que fueron invitados a China desde 1951 hasta 1966 (es decir, en el inicio de la llamada Revolución Cultural). En este sentido, nos proponemos indagar los artículos de los intelectuales publicados en revistas, analizando las temáticas que escogieron y los recursos discursivos que utilizaron para superar la dicotomía Oriente/Occidente.

Antes de continuar con el estudio, conviene señalar las particularidades que tuvieron las relaciones internacionales entre China y Argentina para comprender el lugar de estos intelectuales en el acercamiento entre ambos países.

\section{Las relaciones entre China y Argentina: los intelectuales como agentes diplomáticos}

La distancia geográfica entre China y América Latina retrasó el contacto hasta entrado el siglo XX. Los casos de Perú, México y Cuba resultan excepcionales, ya que en estos países los trabajadores chinos, o culies, empezaron a arribar desde mediados del siglo XIX, pero Argentina, por ejemplo, hacia el 1900 contaba con menos de un millar de inmigrantes de origen asiático, casi todos provenientes de Chile o Perú (Oviedo, 2010).

Los primeros contactos a nivel gubernamental se remontan a 1909, cuando el embajador argentino en Francia se comunicó con el gobierno de la dinastía Qing para firmar un acuerdo de amistad y navegación. Sin embargo, la inestabilidad política en ambos países retrasó los lazos bilaterales hasta después de la Segunda Guerra Mundial. Recién en 1945 Argentina estableció relaciones diplomáticas con la República China, en el

\footnotetext{
Entre los estudiosos chinos sobre el tema se destaca el trabajo de Zhou Ning (2006). Él plantea que a lo largo de la historia hubo tres representaciones en la intelectualidad europea: el Imperio de Gran Khan, el Reino de China y el Imperio de Confucio. El Imperio de Gran Khan representa la recepción europea de la dinastía mongol (por ejemplo, Marco Polo), mientras que el Reino de China es la percepción de Occidente, a partir del siglo XV, tanto del grado de civilización y desarrollo técnico como del gobierno centralizado y formalizado durante la dinastía Tang. La obra más representativa de esta etapa es Historia del Gran Reino de China de Juan González de Menzona. Por último, el Imperio de Confucio, ya no se centra en la cuestión material, sino en el conjunto de ideas y valores filosóficos que caracteriza a la primera interpretación francesa e inglesa del Extremo Oriente. Para los intelectuales de la Ilustración, como Voltaire, la filosofía moral de Confucio formó un estado monárquico iluminado, una nación razonable y una cultura delicada.

Coincidimos con Marshall Berman cuando afirma que la modernidad es un fenómeno complejo que implica una transformación del entramado social, las relaciones económicas y una nueva experiencia del entorno y del tiempo. En este sentido, comprendemos que la imagen tradicional y orientalista sobre China ha indagado sobre los valores y las culturas tradicionales, mientras que la "imagen moderna" se concentra en las problemáticas sociales, económicas y políticas de una sociedad en tiempo presente.
} 
marco de la formación de las Naciones Unidas, pero estos vínculos fueron interrumpidos en 1949, cuando el gobierno de Juan Domingo Perón decidió cerrar la representación argentina en Shanghái ante la situación política del país oriental. Desde ese momento y hasta 1972, Argentina no tuvo relaciones formales con China continental (Oviedo, 2010).

A pesar de esta clausura de legaciones, durante los años cincuenta y sesenta se mantuvieron redes comerciales y culturales a nivel informal entre Argentina y la RPCh. En esta etapa, los intelectuales pro-China jugaron un rol significativo. Durante la primera década, este grupo estuvo formado por simpatizantes del marxismoleninismo que pertenecían a distintas expresiones del campo cultural: periodistas, escritores, poetas, pintores y profesionales. Algunos de ellos eran adherentes activos del Partido Comunista, pero otros simpatizaban con el socialismo internacional sin pertenecer orgánicamente a ninguna organización política.

En la historia argentina, no hubo sinólogos de renombre ni misioneros, comerciantes o militares que hayan visitado China. De hecho, según el estudio de Rosario Hubert, los grupos de izquierda invitados al país fueron el primer contacto y la primera producción intelectual directa de los latinoamericanos sobre China (Hubert, 2017).

La imagen que construyó la izquierda argentina se basaba en la universalidad, a la vez que marcaba la especificidad del país asiático. Por un lado, estuvo en estrecho vínculo con fenómenos globales, como la extensión del marxismo en el campo cultural de posguerra, pero también formaba parte de los conflictos locales del comunismo hacia fines de los cincuenta y principio de los sesenta.

La segunda mitad del siglo XX en Argentina estuvo signada por el surgimiento y proscripción del peronismo. La división entre los partidarios de Juan Domingo Perón y sus opositores, junto con la intervención militar del sistema político, marcaron el desarrollo de la historia reciente del país. Durante este periodo, una nueva izquierda estaba en proceso de formación, atraída por las perspectivas del socialismo en Rusia, China y más tarde, Cuba.

Esta izquierda marxista-leninista, enfrentada a la pasividad del partido tradicional, comenzó a trazar vasos comunicantes con la militancia peronista en un fenómeno de confluencias que caracterizó la larga década de los sesenta. Los miembros de esta izquierda se interesaron por el país asiático, pero no eran directamente entendidos como maoístas. De hecho, Brenda Rupar (2020) señaló que esta categoría política apareció en el país sudamericano con la creciente conflictividad social hacia fines de la dictadura militar de Juan Carlos Onganía (1966-1970).

La RPCh, luego de su fundación en 1949, para superar el aislamiento político y económico impuesto por el bloque occidental, aplicó una estrategia internacional que se conoce como "diplomacia popular". Su primer objetivo era extender el sistema de alianzas a los países asiáticos, africanos y latinoamericanos. A través de programas de radio, panfletos, revistas, periódicos, libros, invitación de viajes y entrenamientos, China ejercía su influencia a través de los grupos de izquierda. En ese periodo, los intelectuales argentinos podían conseguir en español las publicaciones Pekíni informa, China reconstruye, Boletín sinjua, debido al financiamiento de Pekín en su edición y distribución.

A mediados de los años cincuenta, distintos actores culturales conocieron China de primera mano. Los primeros viajeros argentinos pertenecían al Movimiento Mundial por la $\mathrm{Paz}^{5}$. Luego, una delegación argentina fue invitada para presenciar el décimo aniversario de la fundación de la "Nueva China". En 1960, una agencia del gobierno maoísta, la Asociación de Relaciones Exteriores de China, estableció una oficina que tenía como objetivo incentivar los vínculos con el subcontinente: la Asociación de Amistad entre China y América Latina. En respuesta, distintos actores culturales buscaron incentivar el establecimiento de organizaciones políticoculturales que propiciaran el intercambio.

De esta manera, se estableció la Asociación de la Cultura China de Argentina, que desde 1963 empezó a realizar distintas actividades de difusión, como la edición de una revista propia. En este tipo de publicaciones, los viajeros dejaron por escrito sus experiencias en el país asiático.

En los últimos años, aparecieron nuevos estudios que arman el panorama de estas revistas relacionadas con el surgimiento del maoísmo en Argentina (Celentano, 2014). También hay otros que analizaron los testimonios de viajeros desde una perspectiva literaria y sinológica (Hubert, 2017) y algunos que analizaron las revistas en su lógica de publicación, así como también profundizan en el papel de la literatura y cultura en el acercamiento de relaciones bilaterales (Montt Strabucchi, 2016; 2020). Sin embargo, no existen análisis sobre las representaciones de la "nueva China" en base a los textos publicados en estas revistas.

Para este estudio, seleccionamos ejemplares de las revistas mencionadas. El criterio de selección de los textos parte del contenido referido a la actualidad de la RPCh y el interés de sus autores en presentar una experiencia de primera mano. Esta última característica ilumina sobre qué aspectos resultaban de mayor interés para los latinoamericanos y cuáles eran los atributos que buscaban destacar.

Los que dejaron testimonios son Oliver y Frontini (1955); Tuñón (1954), y Warschaver (1955).

Los principales miembros son: Senador augusto G. Bayol, diputado nacional Berta F de Ferrari, diputado provincial Armando Tejada Gómez, Miguel Lombardi de la Asociación de la Cultura China en Argentina, Bernardo Morera, prosecretario de la Federación de Empleados de Comercio, Mario Ferdman, escritor, representante de la juventud, Jorge E Loureiro. Véanse Cultura China (1960). 
Hemos seleccionado tres revistas que se difundieron en este periodo y tienen una importancia inherente para el tema que planteamos. Primero, la revista Cultura China, difundida por la Asociación de Amigos de China, abarcaba literatura y arte, además de las transformaciones materiales de la República Popular? Segundo, Cuadernos de Cultura, publicado por el Partido Comunista argentino, en sus ediciones 34, 49 y 54, hizo reportajes de gran extensión sobre el país asiático ${ }^{8}$. Uno de ellos se dedicó a las conmemoraciones del décimo aniversario, presentando distintos tipos de logros. En tercer lugar, Capricornio también publicó crónicas de los viajeros a China9.

La metodología que aplicamos utiliza herramientas provenientes del análisis del discurso para destacar las representaciones de la otredad en estos escritos. Como señaló Edward Said, la construcción imaginaria de otro culturalmente distinto está relacionada con el contexto de producción en el que intervienen factores económicos, sociales y culturales.

La mayoría de los escritores e intelectuales del período muestra cierta admiración por la Revolución China, reseñando los resultados de sus políticas, a través de datos oficiales y testimonios brindados por los mismos actores de gobierno. Esto puede ser leído como un acto performativo del lenguaje, una expresión de fe en el sistema socialista internacional. Pero, al mismo tiempo, resulta una crítica vedada al país de origen. De hecho, muchas veces oponían las prácticas del Partido Comunista chino a las del gobierno peronista.

Por último, muchos de los intelectuales emprendieron una estrategia discursiva que buscaba enfatizar los aspectos comunes entre países, basándose en la solidaridad de los pueblos oprimidos que pregonaba el Movimiento del Tercer Mundo (Bergel, 2015). Así, algunos viajeros planteaban similitudes entre los pueblos originarios americanos con los nativos de los pueblos montañosos chinos, y los de las estepas pampeanas con los pobladores de las llanuras de Mongolia.

Teniendo en cuenta lo expuesto, hemos dividido las secciones de acuerdo con los ejes de interés que manifestaron sus autores: la materialización del pueblo chino como sujeto político, económico y cultural de la "Nueva China". A continuación, indagamos sobre los recursos textuales que utilizaron para superar la oposición Oriente y Occidente. De esta manera, nuestra lectura busca dar cuenta de la paulatina transformación de las representaciones sobre el país asiático.

\section{El pueblo chino como sujeto del poder político: contraposición entre la democracia "burguesa" y la popular}

Como mencionamos anteriormente, la presencia de intelectuales latinoamericanos en el Extremo Asiático tuvo una explicación política y diplomática. Los viajes eran realizados siguiendo un estricto protocolo y en la compañía de traductores o intérpretes que debían mantener el itinerario pautado. En las estaciones, se ofrecían clases y entrevistas que buscaban exponer los distintos aspectos del gobierno y la sociedad china de ese momento. Esta característica quedó plasmada en la mayoría de los escritos. Los autores concluían que los logros materiales y culturales alcanzados por la RPC se debían al surgimiento de una "democracia popular". De acuerdo con Agosti, las dos lecciones aprendidas de China eran:

primero, que la revolución democrática digna de tal nombre (es decir, la enderezada a eliminar las bases del imperialismo y a destruir la gran propiedad terratenientes) es imposible ya bajo otra conducción que no sea la del proletariado; segundo, que la revolución democrática de nuevo tipo, sin ser todavía la revolución socialista, se inscribe ya en la órbita de la transformación socialista del mundo (Agosti, 1959: 7-8).

En este aspecto, "Líneas fundamentales de la constitución china", de Samuel Shmerkin, publicado en la revista Cuadernos de Cultura, trabaja sobre las peculiaridades de la organización legal y política del país asiático. El autor construye una oposición entre lo que denomina "regímenes de la democracia burguesa" y la "democracia popular" (Shmerkin, 1959: 42).

Desde su perspectiva, el pueblo como sujeto del poder político había sido un compromiso de muchos países occidentales, pero estos nunca lo cumplían con propiedad. Al contrario, Shmerkin en su artículo coloca a la constitución china como la síntesis histórica de esta contradicción fundamental. Al respecto, dice: "El pueblo chino no ha conocido jamás ni por asomo, una democracia tan vasta y profunda como la que le asegura la Constitución de 1954" (Shmerkin,1959: 44).

Según Dangdai, esta revista publicó sólo dos ediciones en el año 1954 y 1955. Sin embargo, hemos encontrado en CeDInCi (Centro de Documentación e Investigación de la cultura de Izquierdas en Argentina) el número 2 de la segunda edición del julio de 1960 . Este dato demuestra que, por lo menos, se publicaron dos números en esta etapa.

Cuadernos de Cultura es una revista cultural del Partido Comunista argentino. Se publicó con una frecuencia irregular entre 1954 y 1985 . Su director Héctor Agosti visitó China y dedicó un número especial al país asiático.

Capricornio. Literatura, arte y actualidades es una revista que se publicó en 1953, 1954 y 1965 . Promovió ese debate e impulsó la reflexión sobre la situación de la literatura argentina y latinoamericana. Su director era Bernardo Kordon, escritor de izquierda, integrante de la Asociación de Intelectuales, Artistas, Periodistas y Escritores (AIAPE) (Celentano, 2007). 
A continuación, señala cuáles son los atributos constitucionales de ese ejercicio directo del poder. Primero, "todo el poder en la República Popular China-dice el art. $2^{\circ}$ pertenece al pueblo, personificado por la Asamblea Nacional de Representantes Populares de China y las Asambleas locales de representantes populares." Segundo, "todos los órganos del Estado deben apoyarse en las masas populares, mantener un contacto estrecho y permanente con ellas, prestar oído a su opinión y estar bajo su control (art.17)." Tercero, "los representantes del pueblo disponen del más amplio derecho de investigación (...) a la que todos los órganos del Estado, las organizaciones populares y los ciudadanos tienen el deber de facilitar los datos y documentos necesarios (art. 35)". Cuarto, "tienen, asimismo, el derecho de interpelación al Consejo de Estado (poder ejecutivo), a los ministerios y a los comités y comisiones adjuntas al Consejo de Estado, todos los cuales están obligados a responder (art.36)". Quinto, "Los diputados (...) responden ante el pueblo, por intermedio de los órganos que los eligieron (...) esos órganos pueden revocarlos y sustituirlos en cualquier momento (art.38)" (Shmerkin, 1959: 44).

En este sentido, el autor desarrolla dos opuestos en el concepto de democracia a través de la participación política del pueblo: por un lado, la "verdadera" (socialista) y por el otro, la "falsa" (burguesa). Así, las afirmaciones sobre China significan una crítica al sistema político del país de origen.

Shmerkin también aprecia las regulaciones de derechos y el bienestar de los trabajadores. Enumera los derechos de los que gozan los hombres y las mujeres (Shmerkin, 1959: 46) y los compara con la reforma constitucional argentina de 1949. El autor considera que la constitución aprobada por el peronismo comprendía el derecho al trabajo, pero no impedía a nadie caer en la desocupación y a ningún desocupado "morirse de hambre". Mientras, en China, el Estado hacía esto efectivo mediante el desarrollo planificado de la economía, el aumento gradual del número de trabajadores ocupados en la producción, el mejoramiento de las condiciones de trabajo y la elevación del salario real (Shmerkin, 1959: 46-47).

De esta manera, el autor tomaba la constitución política del país asiático para hablar sobre determinado aspecto en su país de origen. Vale que recordar que muchos de los intelectuales de la izquierda pro-China tenían una evaluación negativa del gobierno de Perón, al que percibían como un gobierno "pactista", es decir, que buscaba un acuerdo entre clases antagónicas ${ }^{10}$.

\section{El pueblo y la riqueza: transformaciones económicas de la "Nueva China"}

Otro de los elementos clave de la representación de la China posrevolucionaria fue la dimensión económica. Los viajeros de esos años reafirmaban los logros materiales alcanzados durante las primeras décadas, al punto que lo definían como "un milagro económico". La nota de Walter Weber, "La expansión industrial", publicada en la misma revista de 1959 en la que publicó Sherkin, se concentra en este aspecto.

De acuerdo con el autor, el primer plan quinquenal (1953-1957) de China intentaba crear las bases para la industrialización socialista del país, concentrando los esfuerzos en la creación de una industria pesada. Sobre la política del Gran Salto Adelante, iniciada en 1958, decía: "Fue de una magnitud tal que se puede afirmar, sin temor a equivocarse, que la cantidad se transformó en cualidad, es decir, se produjo un camino, un salto cualitativo" (Weber, 1959: 54).

En los escritos, este proceso solía ser presentado como un caso único, sin precedentes en la historia. Los viajeros exponían el desarrollo chino con los datos oficiales del gobierno. Por ejemplo, en el artículo citado se afirmaba: "En vano se buscará en la historia económica del mundo un país que haya incrementado la producción industrial en un 66\% y doblado la cosecha global de cereales en un solo año" (Weber, 1959: 54). A continuación, agregaba: "China no ya en 1972 o 1975 sino en 1960 superará a Inglaterra y a la Alemania Federal, convirtiéndose en la tercera potencia industrial del mundo" (Weber, 1959: 54).

El autor utilizaba las cifras provistas por los organismos oficiales de modo acrítico y a través de expresiones como las ya citadas manifestaba fascinación sobre el proceso de industrialización acelerado. Atribuía estos éxitos al triunfo de un nuevo sistema político. Incluso elogiaba el Gran Salto Adelante, considerado por diversos autores, una de las causas de la hambruna que sufrió el país a fines de la década del cincuenta y principios de los sesenta. Las palabras de otro viajero de la época, Héctor P. Agosti, también mostraban el mismo optimismo exagerado: "A diez años del establecimiento de la República Popular, China es ya una potencia mundial de primera categoría" (Agosti,1959: 8).

El escritor brasileño Josué de Castro editó en Argentina Geografía del hambre, un libro en el que asegura que el hambre fue derrotada en China y que esto constituía uno de los fenómenos sociales más impresionantes de la historia (Lebdinsky,1960: 63). Determinaba, además, que la mejora de la producción se reflejaba también en la salud del campesinado y la población marginal de las ciudades.

Estos juicios estaban justificados por las visitas organizadas por el Partido Comunista chino. Para los intelectuales argentinos, las aldeas eran muestras directas del microcosmos social del país y expresaban su

El Partido Comunista y la Unión Democrática, en las elecciones de 1946, votaron en contra de Perón. Los socialistas clasificaron a Perón como un dictador y un demagogo (Altamirano, 2006:13 y 52). 
desarrollo material. De hecho, los testimonios transcritos en los artículos solían marcar un antes y un después de La Liberación. En el pueblo Tien Choeng, los jefes de la aldea contaban:

Antes, 18 familias terratenientes poseían la mitad de todas ellas. El campesino medio tenía 2 mu y medio de tierra: el campesino pobre sólo medio mu. Los que no tenían ni medio mu trababan para los terratenientes como peones; no tenían suficiente alimento ni harina blanca para comer. ...En 1949, se proclama la Reforma Agraria....ahora todos tienen tierra y trabajan con alegría...En 1950 faltaba abono, implementos, semillas. El gobierno nos ayudó prestando 28 millones de yens. Luego en 1951, otra vez nos prestó 140 millones de yens. La aldea compró 29 molinos de agua, 42 animales de tiro y 20 carros y se construyeron 65 nuevas habitaciones de vivienda. Aumentaron las tierras irrigadas a $600 \mathrm{mu}$, se excavaron 5 pozos de agua." "No sólo estamos en pie económicamente sino elevados políticamente (Warschaver, 1955: 23-24).

Fina Warschaver también notó que la vida había mejorado económica y políticamente:

Ahora comen grano fino todos los días: pueden compararse un saco acolchado cada año. Y, sobre todo, ahora pueden hablar, pueden dirigir sus propios asuntos y participar en el gobierno de la aldea (Warschaver, 1955: 24).

De hecho, en ninguno de los textos reseñados, hay una mención negativa a los años del Gran Salto Adelante. En todos los viajes, los testimonios chinos expresaban las dificultades que padecían antes del establecimiento de la República Popular y marcaban una oposición con el presente. Esta narrativa es constante en la mayoría de los testimonios de viaje.

Incluso, cuando los argentinos realizaban preguntas o buscaban salirse del itinerario pautado geográfica y temáticamente, la respuesta era similar. Uno de los intelectuales argentinos le preguntó a su traductor Xiao Cai sobre la historia de su familia. Su respuesta fue un relato sobre su extrema pobreza hasta que todo mejoró con el advenimiento del Partido Comunista y él pudo llegar a la universidad (Glas, 1955).

Esta comparación entre la nueva y la vieja China no sólo era el método usual para presentar el éxito del gobierno, también constituía un estilo narrativo. De esta manera, se interpretaban las transformaciones económicas como resultado de la superioridad moral del sistema socialista. Tal como afirman alguno de los escritos de la época, la reforma agraria trajo una "liberación de la fuerza de trabajo". "Nada se hace mediante violencia alguna. Todo es logrado por la persuasión y el convencimiento", decía (Oliver y Frontini. 1955: 92). En definitiva, los autores comprendían que los cambios en las condiciones materiales eran el resultado directo de una transformación en la concepción política.

\section{Entre la tradición y el surgimiento de un arte popular: la visión de los argentinos sobre la cultura en la China posrevolucionaria}

Quizás, uno de los aspectos más sobresalientes de estos testimonios de viaje está vinculado al campo de acción de estos actores sociales: la cultura. En esta etapa, los viajeros argentinos se interesaron por la cultura tradicional (una característica relacionada con el orientalismo tardío). Esto, como ha señalado Hubert (2017), podría explicarse por la falta de una tradición sinológica o de intercambios culturales sin antecedentes inmediatos. No obstante, los autores intentaron establecer vasos comunicantes entre las imágenes de una cultura milenaria y lo que observaban como el desarrollo de una "cultura popular".

Es decir, lo primero que observaban era la relación entre cultura y política, ya que los artículos analizados hacían énfasis en los resultados de las políticas de alfabetización. Al respecto, Warschaver mencionaba: "Había, en 1949, casi un 85 por cierto de analfabetos en China. Estas son cifras suficientemente condenatorias del antiguo régimen" (Warschaver, 1955: 25). Otros, incluso, señalaban que el crecimiento de la población lectora se debía a las nuevas estrategias pedagógicas ("Nuevo método contra el analfabetismo", 1954: 35).

En este sentido, las crónicas de viaje notaban que la educación era el resultado del "deseo y el entusiasmo espontáneo del pueblo" (Peluffo, 1961: 78). Uno de los viajeros describía que en el tren se veían trabajadores, campesinos y soldados, absorbidos en juegos de cartas que llevaban palabras escritas. En este juego ganaba el que distinguía la mayor cantidad de las palabras ("Nuevo método contra el analfabetismo", 1954).

Al mismo tiempo que se planteaban los avances educativos, las publicaciones ofrecían largas reseñas sobre la herencia de la cultura tradicional. Por ejemplo, la revista Cultura China en uno de sus números presentó en detalle las expresiones artísticas, incluyendo literatura, teatro, cine, entre otras. Bernardo Morera sostenía que la violenta occidentalización no había desplazado en el alma china los tesoros de su arte ni las modalidades acendradas de su pueblo (Cultura China, 1960).

De hecho, para la mayoría de los intelectuales latinoamericanos, esta fue una diferencia sustancial entre la Revolución China y otras formas del comunismo, como el soviético. Esta percepción se mantuvo incluso en los 
escritos más tardíos ${ }^{11}$. En los itinerarios, las sucesivas exposiciones de arte folclórico eran comprendidas como "auténticas expresiones del pueblo". Es decir, derivaban el rol de las artes de la identificación del campesinado y el proletariado como protagonistas del devenir histórico. Esta afirmación se vinculaba con el discurso de Mao Zedong proferido en el Foro sobre Arte y Literatura en las cuevas de Yennan en 1942. Allí, había afirmado que el objetivo de las expresiones artísticas era "servir al pueblo" (Mao, 1991). Al respecto, en uno de sus artículos, Kordon afirmaba que todos los trabajadores se habían convertido en artistas:

Ya no son los pintores, sino todo un pueblo, el que practica el dibujo tradicional con tema contemporáneo. Obreros, campesinos y soldados no son los temas, sino también los ejecutores que exponen en miles de ciudades y comunas populares. El sistema que no teme dar un fusil a cada hombre ( 250 millones de milicianos), tampoco se inquieta de que cada obrero o campesino empuñe el pincel que en China puede emplearse indistintamente para dibujar o escribir (Kordon, 1965: 12).

En este sentido, los artículos de Kordon dejaban entrever las estrategias de proletarización de la cultura y pensaban en el arte como una forma de manifestación de la "autoconciencia" de las clases trabajadoras. Según el escritor, esta nueva forma de cultura rompía las barreras entre lo que se consideraba "artes de elite" y "artes populares", mezclando el trabajo físico con el intelectual. A su vez, los artistas debían incorporarse al espacio de la fábrica y acompañar el tiempo de ocio y esparcimiento de los trabajadores.

La mayoría de los viajeros de este periodo percibían estas manifestaciones como una experimentación del rol de las artes en la sociedad revolucionaria, un debate que marcó el campo intelectual en América Latina desde fines de la década del cincuenta hasta los años setenta. Los viajeros argentinos resaltaban la incorporación de los artistas a las labores manuales. Era decisión voluntaria de los artistas tratando de representar la nueva china desde un ángulo del pueblo.

Un artículo dedicado al cine en China afirmaba lo siguiente: "Es común que los actores participen de la vida del sector de la población al que deben representar" ("Cinematografía de China", 1955: 43). A continuación, se relataba una historia que ejemplifica el vínculo propuesto entre los agente de la cultura y el pueblo:

Una actriz que debía encarnar el papel de una obrera textil pasó tres meses en una hilandería convirtiéndose en una experta hilandera. También los libretistas toman contacto directo con la vida de los ambientes que han de describir ("Cinematografía de China", 1955: 43).

El artículo ponía escena el vínculo que debían tener los intelectuales y artistas con los miembros de la clase trabajadora. A nivel discursivo, esta estrategia colocaba a China como un horizonte revolucionario, donde el cambio político había impulsado una transformación universal que se expandía desde la economía hasta las artes. En este sentido, las narraciones funcionaban como argumentos de un debate sobre el rol del artista en las sociedades revolucionarias. El escrito concluía con una historia que representaba las enseñanzas que los artistas podían aprender del pueblo. Para reproducir con "fidelidad" el ambiente laboral, ciertas películas eran exhibidas a los trabajadores y obreros antes de su estreno oficial. En una de estas proyecciones, se veía a un obrero portuario que, luego de ser golpeado por su patrón, se largaba a llorar. Los obreros presentes en la exhibición, al parecer, refutaron esta escena diciendo: "En esos días, los golpes eran más frecuentes que la comida; las lágrimas hacía tiempo que se habían secado" ("Cinematografía de China", 1955: 44).

El artículo concluía con una moraleja que indagaba sobre las enseñanzas que los proletariados podían trasmitir a los artistas. La función de estos artículos no sólo consistía en figurar un horizonte imaginario donde había triunfado la revolución, sino también eran un ejemplo sobre el rol popular de las artes, que se debatían los intelectuales en América Latina. Es decir, las expresiones de proletarización de las artes al mismo tiempo que intentaban ser un ejemplo aleccionador para la misma comunidad literaria, funcionaban como un argumento sobre la condición intelectual latinoamericana.

Como veremos en el siguiente inciso, uno de los aspectos distintivos de estos artículos era establecer una relación, un vínculo que planteara una similitud entre los problemas (y posibles soluciones) de China para América Latina.

\section{Las antípodas se encuentran: la lógica de las representaciones sobre China}

Como afirma Axel Gasquet (2006), la Primera Guerra Mundial y la inmediata posguerra implicaron una pérdida del prestigio europeo entre los intelectuales latinoamericanos que buscaron alternativas intelectuales

\footnotetext{
Cabe mencionar que muchos intelectuales argentinos no diferenciaban la alta cultura tradicional y la cultura popular de China, por eso no sabían que la cultura imperial, siendo la parte más dominante de la historia, se iba marginando por el nuevo gobierno, al punto de la destrucción patrimonial. Lo que sucedió fue una desastrosa demolición de la arquitectura antiguas y una rectificación contra la derecha que también involucra el sector de la cultura tradicional (Song, 2014; Andrews, 1990).
} 
y artísticas más allá del viejo continente. Los estudios de Martín Berguel (2015) analizan cómo la imagen común de América Latina y los pueblos de Asia y África que luchaban contra el imperialismo europeo forjó una construcción paulatina durante la primera mitad del siglo XX.

En nuestra investigación, hemos notado que la estrategia discursiva que vinculaba a ambos polos geográficos fue incrementándose a partir de fines de la década de los cincuenta (sobre todo después de la Revolución Cubana en 1959). En sus escritos, los intelectuales tendían cada vez más a equiparar los problemas comunes entre los dos países, su posición periférica en el sistema mundial, como también la posibilidad de aplicar modelos (revolucionarios) que provenían del país asiático. Esto se tradujo en una mirada que rastreaba las similitudes entre los pueblos, sus historias e incluso los paisajes.

Kordon, por ejemplo, afirmaba que las estepas mongolas trasmitían una imagen parecida a la de su propio país: “iTanto andar -afirma en un texto de mediados de los sesenta- para sentirme tan cerca de casa! Tuve que llegar al otro extremo del mundo para ver repetirse en las estepas de Mongolia el paisaje lunar de nuestro Altiplano" (Kordon,1965: 13).

Esta analogía de las estepas con el terreno pampeano se completaba con el parentesco entre los pueblos mongoles con las "indias bolivianas" y los "gauchos" argentinos:

Hombres y mujeres visten relucientes sedas solferinos y verdes, con fajas violentas y naranjas - los mismos colores que adoran las indias bolivianas. Todos calzan las ricas botas del cuero repujado, con las puntas curvadas hacia arriba (...). Aquí se trata del amor del mongol por su caballo, por cierto, pasión compartida por los gauchos (Kordon,1965: 15).

De la misma manera, el ensayista y filósofo Juan José Sebreli establecía que Shanghái era una ciudad paralela a la capital argentina. Él consideraba que la influencia francesa y europea, el supuesto esplendor mercantil de ambas urbes a principios del siglo XX, las colocaba en la misma posición como bastiones de la oligarquía:

Shanghái, como Buenos Aires, con sus violentos contrastes de lujo y miseria extremos, era la gran ciudadpuerto de un país dominado por el extranjero, un trozo de Europa caído en medio del Tercer Mundo, un bastión del capitalismo en el corazón del subdesarrollo, el artificial centro de refinamiento creado por los mismos que mantenían al país en un estado de atraso y barbarie. También en Shanghái, como ahora en Buenos Aires, delicadas flores exóticas crecían en el pantano, mandarines que mediaban en los negocios de los dominadores con la excusa de fusionar la cultura oriental y la occidental, también en Shanghái como en Buenos Aires, una gran parte del pueblo era arrojada por la desocupación al submundo de la picaresca (1965: 1).

La similitud del paisaje, las mismas condiciones materiales, el parentesco de ambos pueblos tendían a construir una identificación (y, al mismo tiempo, marcaban que el cambio político también era posible en el país de origen). Esta estrategia se mantiene a lo largo del ensayo de Sebreli:

Oigo hablar frecuentemente español en el Hotel de la Paz, sobre las mesas del salón de lectura hay revistas chinas traducidas al español y una vez, una camarera china, nos sorprendió cantando en español el estribillo de una canción cubana. Siento que aquí ser latinoamericano es un timbre de honor, se espera mucho de nosotros. China es, en este espacio, el reverso de Europa, donde hablar español es un estigma: en París, en Londres, en Hamburgo los trabajadores más bajos, las criadas y los peones son inmigrantes españoles. La dignificación del idioma español nos está mostrando que aquí en China ha triunfado la rebelión de los más pobres entre los pobres del mundo (1965: 3).

A través del uso del español, Sebreli enfatizaba un sentido de igualdad y unión con el pueblo chino. Este acercamiento era una de las bases constitutivas del Movimiento del Tercer Mundo.

\section{Conclusión}

La izquierda argentina presentaba, a través de distintos recursos discursivos, los logros de la República Popular China. Para ellos, el triunfo de la Revolución China implicaba una transformación universal, que tenía sus repercusiones en no sólo en la política y en la economía, sino también en la manera de pensar el vínculo entre arte y sociedad. Curiosamente, esta imagen romantizada, a su vez, proponía un horizonte común entre los pueblos latinoamericanos y asiáticos.

Esta representación difería de la representación clásica del orientalismo europeo que consideraba a Oriente como inferior o atrasado. Al mismo tiempo, rompía el binarismo entre ambos hemisferios del globo. El discurso basado en la igualdad y amistad servía como base de una expresión política. En este sentido, las crónicas y publicaciones tendían a mostrar una confluencia, es decir, un punto en común como expresiones de un posible 
destino compartido. En un país lejano y durante el inicio de la Guerra Fría, esta forma de presentar y difundir la imagen de China tuvo un valor significativo, al plantear una mirada distintas sobre la otredad.

Esta nueva imagen ponía como protagonistas al pueblo chino. De hecho, los escritos comparten una representación común: el pueblo había tomado la conciencia como sujeto histórico y se transformaba en el principal actor político, cultural y económico. Esta representación fundamentaba un sentimiento común como pregonaba el Movimiento Tercermundista. Al mismo tiempo, identificaba la condición de los oprimidos como un factor común para estrategias conjuntas.

La mayoría de estos escritores pertenecían al amplio abanico de las izquierdas, pero no estrictamente al maoísmo. Por eso, la representación no estaba centrada tanto en la revolución como en las condiciones actuales a través de expresiones de simple admiración o las transcripciones de datos sin contrastar. Al mismo tiempo, se trataba de una crítica encubierta a la condición del propio país, al que identificaban con los valores europeos y a la falsedad de una democracia burguesa que decía beneficiar al pueblo. Esto implicaba una identificación de problemas comunes y respuestas posibles que superaba las dicotomías del orientalismo.

Esta nueva mirada entre los países del denominado "Tercer Mundo" rompía con el binarismo que definía la modernidad occidental tanto sobre la otredad como sobre el orden internacional. Al mismo tiempo, identificaba al país asiático como un horizonte revolucionario, un pueblo con problemáticas similares a las que se vivían en Latinoamérica. De esta forma, se impulsaban los lazos entre dos países en las antípodas geográficas y un sentimiento común entre ambas naciones.

\section{Bibliografía}

Andrews, J. F. (1990). "Traditional Painting in New China: Guohua and the Anti-Rightist Campaign". En: Journal of Asian Studies, no.49, vol. 3, pp. 555-586. https://doi.org/10.2307/2057771

Alcira, A. (1971). "Cátedras nacionales: Una experiencia peronista en la Universidad," En: Envido, no 3, p. 55.

Altamirano, C. (2006). Peronismo y la Cultura de Izquierda. Buenos Aires: Grupo Editorial.

Ash, R. (1998). Agricultural Development in China, 1949-1989: The Collected Papers of Kenneth R. Walker (19311989). Oxford: Oxford University Press.

Bergel, M. (2015). El oriente desplazado, los intelectuales y los origenes del tercermundismo en la Argentina. Bernal: Universidad Nacional de Quilmes.

Celentano, Adrián. (2007) "Otro signo de la crisis: la revista Capricornio". XI Jornadas Interescuelas/Departamentos de Historia. Facultad de Filosofía y Letras. Universidad de Tucumán, San Miguel de Tucumán.

Celentano, Adrián. (2014). "El maoísmo argentino entre 1963 y 1976: Libros, revistas y periódicos para una práctica política." En: Políticas de la Memoria, Vol.14, pp. 151-165.

Eisenman, J. (2018). Red China's green revolution: technological innovation, institutional change, and economic development under the commune. Nueva York: Columbia University Press.

Gasquet, A. (2015). El llamado de Oriente: Historia cultural del orientalismo argentino, 1900-1950. Buenos Aires: Eudeba.

Gao, M. (1999). Gao Village: A Portrait of Rural Life in Modern China. Honolulu: University of Hawaii Press.

Hubert, R. (2017). "Intelecutal Cartographies of the Cold War, Latin American Visitors to the People's Republic of China, 1952-1958". En: The Routledge Handbook of Literature and Space. Nueva York: Taylor \& Francis, pp. 337-348.

Locane, J.J. y Strabucchi, M.M. (2020). "Cultura china y Capricornio. Dos proyectos pioneros para el comercio simbólico (y material) entre América Latina y China", Revista Izquierdas, $\mathrm{n}^{\circ} .49$.

Mao, Z.(1991). “Discurso ”(在延安文艺座谈会上的讲话), Obras escogidas de MaoZedong Vol.3(《毛泽东选集》第 3卷), Beijing:People's Publishing House.

Oviedo, E. (2010). Historia de Relaciones Internacionales entre China y Argentina 1945-2010. Buenos Aires: Dunkun.

Rupar, B. (2020). "Relatos de viaje a la China socialista. Una relectura de testimonios de viajeros argentinos en los años' 50". Revista Interdisciplinaria de Estudios Sociales, (20), pp. 165-181.

Saítta, S. (ed.) (2007). Hacia la revolución. Viajeros argentinos de izquierda, Buenos Aires: Fondo de Cultura Económica.

Song,W.(2014). "The Aesthetic versus the Political: Lin Huiyin and Modern Beijing". En: Chinese Literature: Essays, Articles, Reviews (CLEAR), vol. 36, pp.61-94.

Strabucchi, M. M.(2010). "The PRCs Cultural Diplomacy towards Latin America in the 1950s and 1960s". En: International Journal of Current Chinese Studies, no.1, p.53-83.

Strabucchi, M. M.(2016). “'Writing about China'Latin American travelogues during the Cold War: Bernardo Kordon's ‘600 millones y uno'(1958), and Luis Oyarzún's ‘diario de oriente, Unión Soviética, China e India'(1960).” Revista Caminhos da História, Vol. 21, no.1, pp. 93-124.

Zhou, N. (2006). 《天朝遥远: 西方的中国形象学研究》(El imperio está lejos: los estudios de representaciones chinas del occidente), Beijing: Pekin Universiy Press. 


\section{Fuentes primarias}

Agosti, H. P. (1959). "Nosotros y la Revolución China". En: Cuadernos de Cultura. nº.43, pp.1-9.

Bayol, A.G. (1960). "Yo estuve en Pekín”. En: Cultura china, n’.2.

Kordon, B. (1965). "China Clara y extraña”. En: Capricornio, no.3, pp. 9-16.

Glas, E. (1955). "La Vida del Estudiante Tsai”. En: Cultura China, n’.2, pp. 46-50.

Lebdinsky, M. (1960). "Josue de Castro, China y el problema del hambre", En: Cuadernos de Cultura, n”.49, pp.58-67.

Mendez, E. (1955). "Examen de conciencia chino". En: Cultura China. no.2, pp.32-38.

Oliver, M.R. y Frontini, N.A. (1955). Lo que sabemos hablamos. Testimonio de la China de hoy, Buenos Aires: Botella al Mar.

Sebreli, J.J. (1965). “Testimonios sobre china”. En: Capricornio. n’.3, pp.1-8.

Shao, C. (1959). "La literatura china actual". En: Cuadernos de cultura, no.43, pp.10-20.

Shmerkin, S. (1959). "Líneas fundamentales de la constitución china”. Cuadernos de Cultura, no.43, pp.42-47.

Peluffo, J. (1961). "Breve esquema de la enseñanza secundaria en la China Republica”. En:Cuadernos de Cultura, $\mathrm{n}^{\circ} .54$, pp.72-79.

Tuñón, R.G. (1954). Todos los hombres del mundo son hermanos. Impresiones de viaje por Moscú, Kiev, Leningrado, Pekín, Tientsin, Nankín, Shangai, Hanchow, Praga, Lidice y una versión de Varsovia. Buenos Aires: Poemas.

Warschaver, F. (1955). "En una aldea china". En: Cultura China. n.2, pp.20-26.

Weber W. (1959). "La Expansión Industrial”. Cuadernos de Cultura. no.43, pp.48-54.

"Cinematografía de China" (1955). En: Cultura China. no.2, pp.39-45.

"Nuevo Método contra el Analfabetismo" (1954). En: Cultura China, no.1, pp.35-39.

"Radio, Impresión, Cine y penetración" (1967). En: Informe de China, n.9, pp.34-39.

"Reportaje de Radio Rivadavia el día 23 de diciembre a la diputada nacional B.F. de Ferrari” (1960). En: Cultura China, $\mathrm{n}^{\mathrm{o}} .2$. 